\title{
Courtship and mating of Scorpiops luridus Zhu Lourenço \& Qi, 2005 (Scorpiones: Euscorpiidae) from Xizang province, China
}

\author{
Jiao GB (1), Zhu MS (1)
}

(1) College of Life Sciences, Hebei University, Baoding, Hebei Province, China.

\begin{abstract}
In the current work, the courtship and mating of Scorpiops luridus Zhu Lourenço \& Qi, 2005 (Euscorpiidae) from Xizang province (Tibet), China, were studied for the first time in the laboratory. Most of the mating behaviors in Scorpiops luridus are not remarkably different from those exhibited by other scorpions. However, for the first time a male pulling a female with its chelicerae to rapidly accomplish the sperm uptake was observed. Additionally, the sexual stinging behavior displayed by the male occurred in the initial stage, not during the promenade stage as previously described in several scorpion species. Through observation and analysis, we speculate that venom injection during sexual stinging is selective, possibly relying on the status shown by the stung scorpion (passive or aggressive). In order to clearly describe the process of courtship and mating, both sequences are represented in a flow chart, while the main behavior components of these processes were identified, analyzed and discussed.
\end{abstract}

KEY WORDS: scorpion, Scorpiops, courtship, mating, behavior.

CONFLICTS OF INTEREST: There is no conflict.

FINANCIAL SOURCE: The National Natural Science Foundation of China (30670254) and the Doctoral Program Foundation of Chinese Ministry of Education (20050075002).

\section{CORRESPONDENCE TO:}

GUO B. JIAO, 180 Wusi Road, Baoding, Hebei Province, China. Phone: +86

13613320215. Email: guobinjiao@126.com. 
Jiao GB and Zhu MS. Courtship and mating of Scorpiops luridus Zhu Lourenço \& Qi, 2005 (Scorpiones: Euscorpiidae) from Xizang province, China. J Venom Anim Toxins incl Trop Dis. 2009;15(1):156

\section{INTRODUCTION}

By analyzing some studies on scorpion reproductive behaviors, we can draw a conclusion that different scorpion species present similar gross structure in courtship and mating. Most of these behaviors have been identified and their possible functions are discussed in two works, The Biology of Scorpions (1) and Scorpion Biology and Research (2). However, terminologies for some behaviors differ between the two works, on account of variations among habits of various authors.

Only 29 of the approximately 1,800 scorpion species described have had their reproductive behaviors studied up to 1990 (1, 3). Subsequently, only a few experiments have been conducted to study the courtship and mating behaviors in other scorpions. For example, Tallarovic et al. (4) first described the courtship and mating in Hadrurus arizonensis (Scorpionidae, luridae). Behavioral components of courtship and mating observations by Ross (5) of Tityus (Atreus) magnimanus (Scorpiones: Buthidae) were presented in an ethogram to delineate their occurrence during mating sequences. Jiao and Zhu (6), researching courtship and mating in Heterometrus petersii, found that one behavior pattern had two functions and that the functions varied among individuals. For example, arm-pulling behavior in Leiurus quinquestriatus (Buthidae) seemed to be associated with the male finding the exact spot on which to deposit the spermatophore, whereas this behavior in Heterometrus petersii helped the female to complete uptake of the sperm as soon as possible.

So far, the courtship and mating behaviors of only four euscorpiid scorpions Euscorpius carpathicus, E. flavicaudis, E. italitus and Megacormus gertschi - have been reported (1). Although the process of courtship and mating is similar among different scorpion families, genera and even species in the same genus, to some extent, their behavior patterns may differ to varying degrees $(1,6)$. Thus, it is valuable to research the reproductive behaviors among scorpions.

Laboratory observations of courtship and mating sequences in the euscorpiid scorpion Scorpiops luridus were conducted from February to May, 2009. Male-female pairs were placed in a mating arena $(60 \times 50 \times 40 \mathrm{~cm})$ with soil substrate as we began observations using two $40-\mathrm{W}$ red bulbs (6). Scorpiops luridus specimens were 
collected from hillsides in Xizang province, China. The adults were 7.0 to $8.9 \mathrm{~cm}$ in length and housed individually in terraria $(30 \times 15 \times 20 \mathrm{~cm})$ that contained some moist cotton balls to maintain humidity. The room temperature varied from 25 to $28^{\circ} \mathrm{C}$.

In order to describe courtship and mating in a sequential and clear manner, the whole process was divided artificially into four stages: initiation, promenade à deux, sperm transfer and termination (4). A flow chart was constructed to demonstrate the sequence of courtship and mating behaviors (Figure 1). The behavioral terminologies identified were modified from Polis and Sissom (1), Benton (2) and Peretti and Carrera (7) (Table 1). The elapsed times of each stage and each main behavior during courtship and mating were represented as ranges. They were presented herein as observational data because only six adult male scorpions were reared in the laboratory.

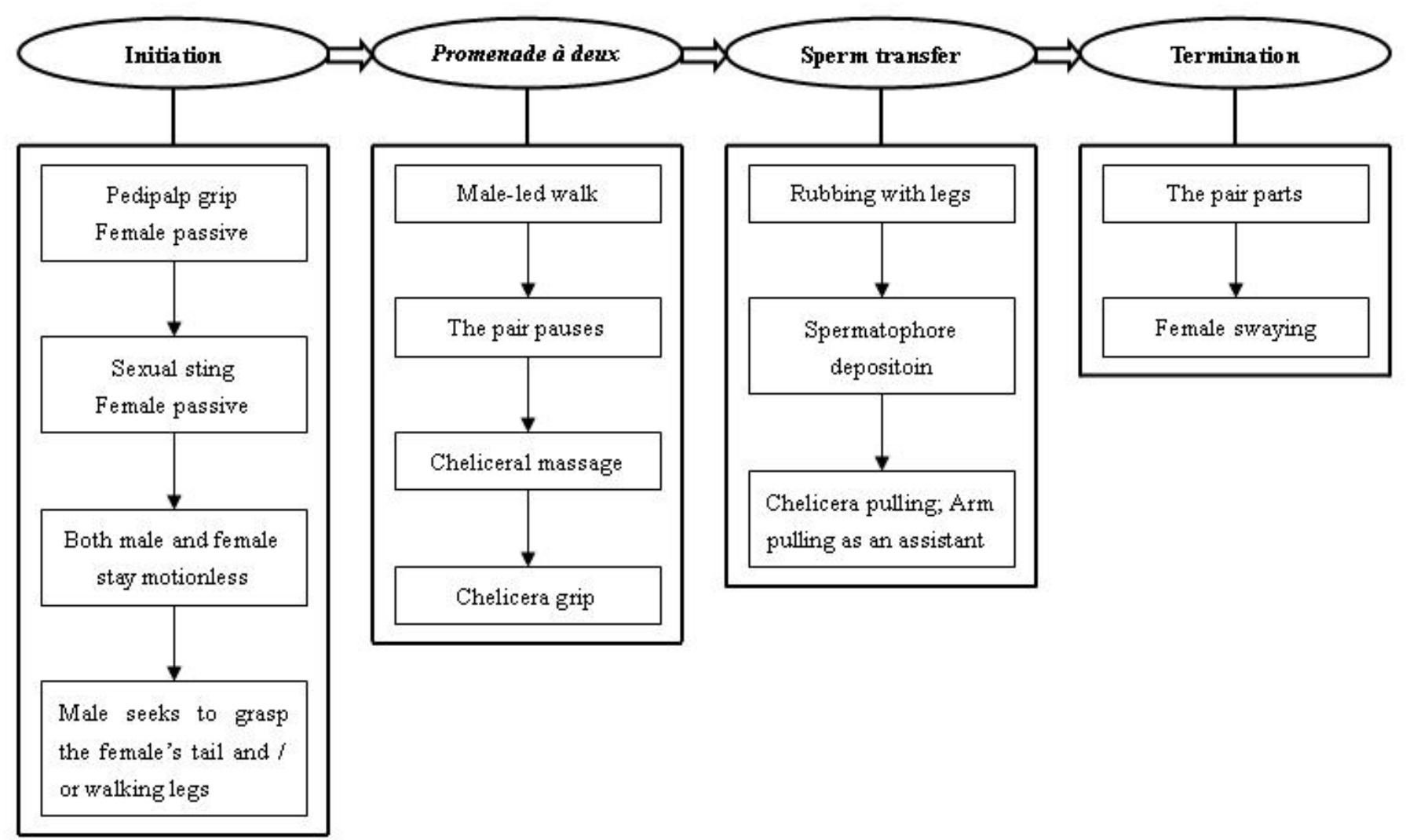

Figure 1. Courtship and mating sequence of Scorpiops luridus. 
Table 1. The main behaviors involved in courtship and mating of Scorpiops luridus, modified from Polis and Sissom (1), Benton (2) and Peretti and Carrera (7)

\begin{tabular}{|c|c|c|c|c|}
\hline Behavior & Sex & Stage & Description & Possible function \\
\hline Pedipalp grip & $\hat{o}-q$ & I , II \& III & $\begin{array}{l}\text { The male usually grasps the } \\
\text { female in a } \\
\text { pedipalp-to-pedipalp grip }\end{array}$ & $\begin{array}{l}\text { Leading the } \\
\text { female as the pair } \\
\text { moves together }\end{array}$ \\
\hline $\begin{array}{l}\text { Sexual } \\
\text { stinging }\end{array}$ & $\hat{o}-q$ & 1 & $\begin{array}{l}\text { The male uses its sting to } \\
\text { puncture the female's } \\
\text { intersegmental membrane of } \\
\text { pedipalp or the first pair of legs }\end{array}$ & $\begin{array}{l}\text { Subduing female } \\
\text { aggressive } \\
\text { behavior }\end{array}$ \\
\hline $\begin{array}{l}\text { Pecten } \\
\text { movement }\end{array}$ & 0 & I , II \& III & $\begin{array}{l}\text { The pectines are spread wide } \\
\text { and sporadically swept across } \\
\text { the substrate }\end{array}$ & $\begin{array}{l}\text { Receiving } \\
\text { information from } \\
\text { the environment, } \\
\text { such as the } \\
\text { female, substrate, } \\
\text { etc. }\end{array}$ \\
\hline $\begin{array}{l}\text { Cheliceral } \\
\text { massage }\end{array}$ & $\hat{o}-q$ & I , II \& III & $\begin{array}{l}\text { The male kneads the } \\
\text { chelicerae, the edge of the } \\
\text { prosoma and/or the } \\
\text { articulation of the pedipalps of } \\
\text { the female with his chelicerae }\end{array}$ & $\begin{array}{l}\text { Making the female } \\
\text { more docile and } \\
\text { receptive }\end{array}$ \\
\hline Chelicera grip & ô- & II \& III & $\begin{array}{l}\text { The male grasps the female in } \\
\text { a chelicera-to-chelicera grip }\end{array}$ & $\begin{array}{l}\text { Leading the } \\
\text { female as the pair } \\
\text { moves together }\end{array}$ \\
\hline $\begin{array}{l}\text { Rubbing with } \\
\text { legs }\end{array}$ & $\hat{0}-q$ & II & $\begin{array}{l}\text { The male moves his first pair } \\
\text { of legs rapidly and rubs the } \\
\text { anterior parts of the female's } \\
\text { ventral prosoma and her }\end{array}$ & $\begin{array}{l}\text { A sexual } \\
\text { stimulation } \\
\text { behavior }\end{array}$ \\
\hline
\end{tabular}




\begin{tabular}{|c|c|c|c|c|}
\hline & & & genital operculum & \\
\hline $\begin{array}{l}\text { Chelicera } \\
\text { pulling }\end{array}$ & $\hat{o}-q$ & III & $\begin{array}{l}\text { The male keeps his legs } \\
\text { immobile and moves them } \\
\text { forward and backward with } \\
\text { low amplitude while grasping } \\
\text { the female's chelicerae with } \\
\text { his own }\end{array}$ & $\begin{array}{l}\text { Assisting female } \\
\text { completing sperm } \\
\text { uptake as soon as } \\
\text { possible }\end{array}$ \\
\hline $\begin{array}{l}\text { Female } \\
\text { swaying }\end{array}$ & q & IV & $\begin{array}{l}\text { The female raises her body } \\
\text { above the ground while slowly } \\
\text { and quickly moving from side } \\
\text { to side and/or backward and } \\
\text { forward and keeps his legs } \\
\text { immobile }\end{array}$ & $\begin{array}{l}\text { Making the sperm } \\
\text { travel farther into } \\
\text { the female's } \\
\text { reproductive tract }\end{array}$ \\
\hline
\end{tabular}

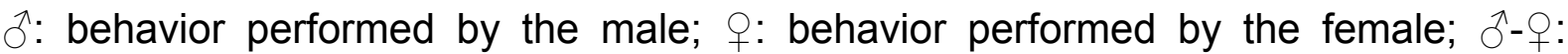
male-initiated behavior that requires female's cooperation

\section{Stage I: Initiation}

The courtship began when the male approached the female and made an attempt to grasp her with his pedipalp chelae. Usually the male prefers to grasp the chelae of the female. Upon or immediately after simultaneously grasping the female's chelae, the male stung the intersegmental membrane of the pedipalp or the first pair of legs of the female (sexual stinging) and stayed motionless for 120 to 300 seconds. It is interesting that the female appeared passive after being grasped and did not present aggressive behavior (such as clubbing) in response to the male's grasp, even after being stung by him. After ceasing, the male sought to lead the female. Sometimes the male actively outstretched his chelicerae to comb her pedipalp chelae, prosoma edge or chelicerae (cheliceral massage) for 30 to 90 seconds before walking. Subsequently, there was an interesting behavior displayed by the male, namely, releasing one of his pedipalp chelae and continuing to hold her chelae with his own; then he attempted to utilize his released pedipalp chelae to grasp her tail (usually) and/or walking legs (less 
frequently), which appeared to serve as a means to judge her morphology (8). We observed that the female always moved around the male in order not to be grasped by him. If he grasped unsuccessfully at her tail for a while or if she became more aggressive than before, he also exhibited "cheliceral massage" behavior. After that, she became more cooperative. After judging the morphology of the female, the male began the male-led walk. During this stage, the male's pectines were usually opened widely and sporadically swept across the substrate (pecten movement), a behavior sometimes displayed by the female.

\section{Stage II: Promenade à Deux}

During this phase, the characteristic behavior was the male-led walk. The male usually moved backward with the female following and, sometimes, backward and forward. The male-led walk was not continuous either with a pedipalp grip or a chelicera grip, and often the pair ceased moving and stayed motionless after walking a short distance. This motionless period was named the "pause" (2). The pause can last 25 to 180 seconds. After that, the male continued to lead the female as she walked following him. If he did not pull her to walk together, the pair continued to stay motionless or he displayed the "cheliceral massage" behavior. If the male grasped the female without a chelicera grip during the pause, he (most frequently) outstretched his chelicerae to comb the pedipalp chelae and/or chelicerae of the female. If the male grasped the female with a chelicera grip during the pause, he continued to grip the chelicera with one of his own and combed her other one with the other of his own.

So during most of this stage, we could observe the sequence of walk-pause-(cheliceral massage)-walk. There was another behavior observed in this stage, rubbing with legs, during which the male moved his first pair of legs rapidly and rubbed the anterior parts of the female's ventral prosoma and her genital operculum, and then the pair stayed motionless for 15 to 120 seconds. Each instance of leg-rubbing behavior consisted of 5 to 12 rubbings and lasted 5 to 15 seconds. There were 15 to 20 rubbing repetitions before sperm transfer. After the motionless phase, if the male could not pull the female to follow his walking, he presented cheliceral massage behavior, after which the female 
became more cooperative. Yet another behavior, chelicera grip, was observed in this stage. The male led the female in walking with a chelicera-to-chelicera grip (chelicera grip) often with an assisting pedipalp grip. Once the female's chelicerae were grasped by the male with his own, the walk was controlled by the cheliearae of the male with assistance from the pedipalp chelae. Once the chelicera grip had become less effective for control, the pedipalp grip began. During this phase, both the male and female displayed the pecten movement behavior. The promenade à deux stage lasted 60 to 90 minutes, depending on the time taken to find a suitable spot for spermatophore deposition.

\section{Stage III: Sperm Transfer}

The male preferred to lead the female in walking by means of a chelicera-to-chelicera grip during this stage. The male-led walks reduced as the moment and site suitable for spermatophore deposition approached. Once a suitable spot was encountered, the male lowered his mesosoma until his genital aperture touched the ground, and then the entire spermatophore was extruded as the male moved his prosoma upward and backward as the sticky basal plate lightly contacted the surface of substrate. Subsequently, the male pulled the female into a proper position over the spermatophore so that her genital opercula were able to take up the sperm. Afterward, another important behavior, chelicera-pulling by the male, was observed. The male pulled the female with a chelicera to chelicera grip (always) and a pedipalp-to-pedipalp grip (usually) for assistance and kept his legs immobile, which was done repeatedly for 20 to 35 times at intervals of 10 to 30 seconds. Each repetition of this low-amplitude behavior lasted about one second.

During sperm transfer, the male apparently did not use sufficient strength to grasp the female's chelae with his own and maintained his balance for successful sperm transfer. In one case, the pair was influenced by surrounding factors during sperm transfer. Although the pair maintained normal mating posture, the male released his pedipalp chelae and kept his chelae open and outside the female's, and sperm transfer continued through chelicera pulling as usual until completing sperm uptake. Prior to 
performing the pulling behavior, the male usually made his third and forth walking-legs push against the substrate using much more strength, similar to the description of Heterometrus petersii by Jiao and Zhu (6), a behavior whose possible function was to prepare for subsequent sperm transfer. The female was passive and just cooperated with the male to help herself take up the sperm as soon as possible during sperm transfer. Before sperm transfer, the male usually displayed the pecten movement behavior while the female did so less frequently. Sperm transfer lasted 30 to 60 minutes.

\section{Stage IV: Termination}

Mating terminated as the female retracted her pedipalp chelae and chelicerae and struggled to break loose from the control of the male. At the same time, the male left the sperm transfer site or just stayed motionless on the spot. Subsequently, the female left the site of spermatophore deposition and raised her body slightly above the ground while slowly moving from side to side and/or backward and forward two or three times with her legs immobile (female swaying), which was only observed in six scorpion species distributed among three families except Scorpiops luridus (1). Then, either the female also stayed motionless or moved a small scope away from the spermatophore after sperm transfer. The female became more aggressive than before as the male tried grasping her after the "courtship".

Most of the mating behaviors in Scorpiops luridus were not remarkably different from those displayed by other scorpions, but male chelicera-pulling behavior that helped the female accomplish the sperm uptake as soon as possible is being described herein for the first time. Basically, the male used arm pulling to assist the female to accomplish sperm transfer in scorpions such as Heterometrus petersii (6). It has never been reported that the male used chelicera pulling to help the female to enable sperm transfer in other scorpions. The chelicera-pulling behavior controlled by the male's chelicerae was of low amplitude, whereas arm pulling was of high amplitude. These two behaviors are visually differentiable.

In the initiation stage, male juddering behavior usually presented by other scorpions 
was never observed in Scorpiops luridus, and clubbing behavior displayed by the female in some scorpions was also never shown by this species after the male had grasped or even stung her.

Only sexual-stinging behavior was clearly displayed by the male during the initiation stage, but, in other scorpions, was shown in early promenade and then sporadically afterward (1). Its possible function was to subdue the normal female aggression, if envenomation occurred after the male stung the female. Interestingly, sexual behavior in Scorpiops luridus was displayed only immediately after the male met the female and sought to grasp her during the initiation stage. Our observations revealed that the male seemed to use sufficient strength at the beginning of sexual stinging. However, the female remained passive after being stung. Subsequently the stinging strength decreased and the sting did not puncture deeply into the intersegmental membrane. Stinging strength may have depended on whether the stung scorpion had been passive or aggressive. In order to determine whether venom was injected into the female in one experiment, we took his aculeus from the intersegmental membrane and found that the aculeus surface was dry. The male seemed not to inject venom into the passive female. So we can speculate that the occurrence of venom injection during sexual stinging could depend on the passivity or aggressiveness of the stung scorpion. If the female was passive during the sexual sting, the male could not inject his venom; if the female was aggressive during the sexual sting, the male was able to inject his venom to subdue her aggressive behavior.

We observed that the male Scorpiops luridus sought to grasp the tail and / or walking legs of the female before conducting the lengthy male-led-walk in the initiation stage. The male possibly judged the female's morphology, a behavior similar to that described by Alexander (8), who, while studying the scorpion Tityus trinitatis, suggested that initiation for some species was stimulated by male recognition of characteristics of the female's anatomy after physical contact was established. She also noted that Tityus trinitatis was markedly sexually dimorphic in both the size and coloration of the metasoma and that during the initial contact the male preferentially grasped the female's tail. This suggested that sexual difference in the metasoma was 
an important factor in sex recognition.

Table 2 compares the mating behaviors displayed by five Euscorpiid scorpions including Scorpiops, and shows that only Scorpiops displayed the chelicera grip, chelicera-pulling and female swaying behaviors. Only Megacormus presented juddering while only Euscorpius performed clubbing. Both Euscorpius and Megacormus presented spermatophore consumption behavior, a behavior not shown by Scorpiops. These findings reveal that mating behavior differed, to some extent, among the three genera.

Although scorpions are highly conserved during evolution, two scorpion species from the same genus may display remarkable different mating behaviors (6). Different species may exhibit different mating behaviors, and the same mating behavior presented by different scorpion species in different stages may perform different functions. So it is remarkably valuable for us to conduct additional experiments to reveal the mating behaviors of other scorpions in future.

Table 2. Comparison of main mating behaviors in three Euscorpiidae genera

\begin{tabular}{c|c|c|c|c|c|c|c|c|c|c}
\hline & JUD & CLU & PEG & CGR & SES & CMA & PEM & CPL & FES & SPC \\
\hline $\begin{array}{c}\text { Euscorpius } \\
\text { carpathicus }\end{array}$ & & + & + & & + & + & + & & & + \\
\hline $\begin{array}{c}\text { Euscorpius } \\
\text { flavicaudis }\end{array}$ & & + & + & & + & + & + & & & + \\
\hline $\begin{array}{c}\text { Euscorpius } \\
\text { italitus }\end{array}$ & & + & + & & + & + & + & & & + \\
\hline $\begin{array}{c}\text { Megacormus } \\
\text { gertschi }\end{array}$ & + & & + & & + & + & & & & + \\
\hline \begin{tabular}{c} 
Scorpiops luridus \\
\hline
\end{tabular}
\end{tabular}

+: behavior observed; behavior displayed by only one genus is marked in red.

JUD: juddering; CLU: clubbing; PEG: pedipalp grip; CGR: chelicera grip; SES: sexual stinging; CMA: cheliceral massage; PEM: pecten movement; CPL: chelicera pulling; FES: female swaying; SPC: spermatophore consumption.

Data for E. carpathicus, E. flavicaudis, E. italitus and M. gertschi from Polis and Sissom 
(1).

\section{ACKNOWLEDGEMENTS}

We would like to thank Dr. J. MacDermott for improving the manuscript.

\section{REFERENCES}

1. Polis GA, Sissom WD. Life History. In: Polis GA, editor. The Biology of Scorpions. Stanford: Stanford University Press; 1990. p. 161-223.

2. Benton TG. Reproductive ecology. In: Brownell PH, Polis GA, editors. Scorpion Biology and Research. New York: Oxford University Press; 2001. p. 288-94.

3. The Scorpion Files [homepage on the Internet]. Trondheim: Norwegian University of Science and Technology; c2001-2009 [updated 2009 Mar 12; cited 2009 Apr 10]. Available from: http://www.ub.ntnu.no/scorpion-files.

4. Tallarovic SK, Melville JM, Brownell PH. Courtship and mating in the giant desert hairy scorpion, Hadrurus arizonensis (Scorpionida, luridae). J Insect Behav. 2000;13(6):827-38.

5. Ross LK. Notes and observations on courtship and mating in Tityus (Atreus) magnimanus Pocock, 1897 (Scorpiones: Buthidae). J Venom Anim Toxins incl Trop Dis. $2009 ; 15(1): 43-53$.

6. Jiao GB, Zhu MS. Courtship and mating in Heterometrus petersii (Thorell, 1876) (Scorpiones:Scorpionidae). Euscorpius. 2009;84(1):1-5.

7. Peretti AV, Carrera P. Female control of mating sequences in the mountain scorpion Zabius fuscus: males do not use coercion as a response to unreceptive females. Anim Behav. 2005; 69(2):453-62.

8. Alexander AJ. Courtship and mating in the buthid scorpions. Proc Zool Soc (London). 1959;133(15):145-69. 